\title{
Effects of facemask therapy on the mandibular retromolar space
}

\author{
A follow-up study
}

Zeynep F. Zor, DDS, PhD, Emine Kaygisiz, DDS, PhD, Can Ates, PhD, Tuba Tortop, DDS, PhD, Sema Yuksel, DDS, PhD.

\section{ABSTRACT}

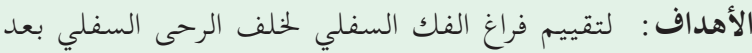

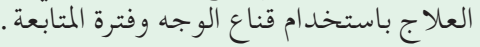

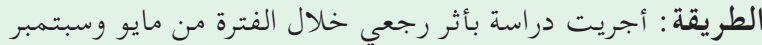

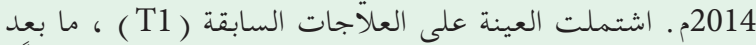

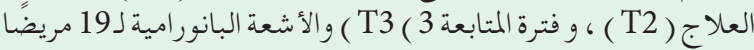

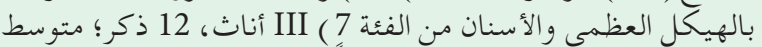

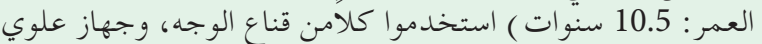

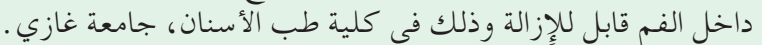

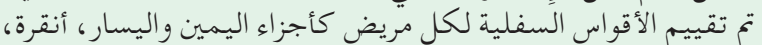

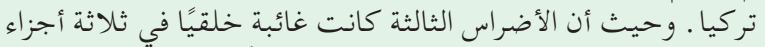

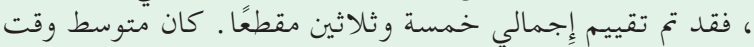

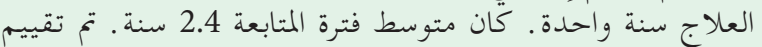

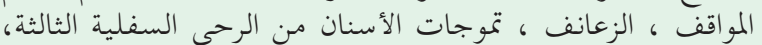

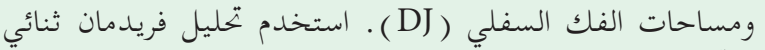

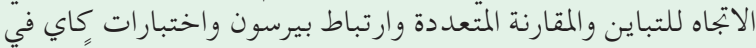

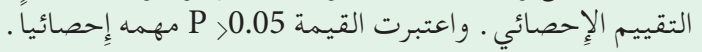

النتائج: ازداد تكاثف الضرس الأول بشكل كبير فقط في فترة

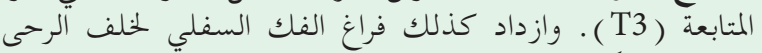

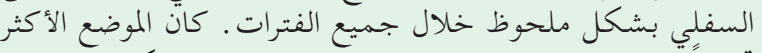

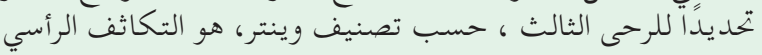

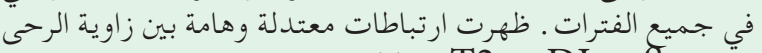

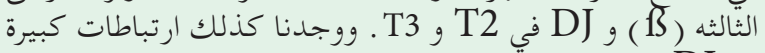

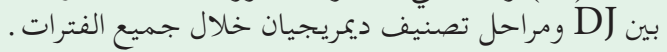

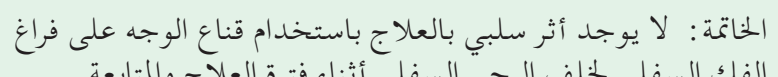

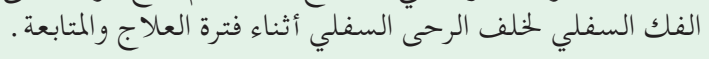

Objectives: To evaluate the mandibular retromolar space after facemask therapy and a follow-up period.

Methods: This retrospective study was conducted between May and September in 2014. The sample consisted of pre-treatment (T1), post-treatment (T2), and follow-up(T3) panoramic radiographs of 19 skeletal and dental Class III patients ( 7 female, 12 male; mean age: 10.5 years) treated with facemask and a removable intraoral upper appliance in the Faculty of Dentistry Gazi University, Ankara, Turkey. Each patient's lower arches were evaluated as right and left segments. As third molars were congenitally absent in 3 segments, a total of 35 segments were evaluated. The average treatment time was one year. The average follow-up period was 2.4 years. The positions, angulations, dental maturations of lower third molars, and mandibular retromolar spaces (DJ) were assessed. Friedman's 2-way Analysis of Variance, multiple-comparison, Pearson's correlation, and Chi-square tests were used for statistical evaluation. A $p<0.05$ was considered as significant.

Results: The angulation of the first molar (Y) increased significantly only in the follow-up period (T3). Mandibular retromolar spaces were increased significantly during all periods. The most commonly determined position of the third molar, by Winter's classification, was vertical angulation in all periods. Moderate and significant correlations were found between third molar angulation( $(3)$ and DJ at T2 and T3. Significant correlations were also found between DJ and Demirjian classification stages during all periods.

Conclusion: Facemask therapy did not have an adverse effect on the mandibular retromolar space during treatment and follow up periods.

Saudi Med J 2018; Vol. 39 (8): 815-821 doi: 10.15537/smj.2018.8.22292

From the Department of Orthodontics (Zor, Kaygisiz, Tortop, Yuksel), Faculty of Dentistry, Gazi University, Ankara; and from the Department of Biostatistics (Ates), Faculty of Medicine, Yüzüncü Yil University, Van, Turkey.

Received 1st March 2018. Accepted 27th June 2018.

Address correspondence and reprint request to: Dr. Emine Kaygisiz, Department of Orthodontics, Faculty of Dentistry, Gazi University, Ankara,Turkey.E-mail: dt.emineulug@mynet.com

ORCID ID: orcid.org/0000-0003-2087-7048 
$\mathrm{C}$ lass III malocclusions are mostly characterized by either maxillary retrognathism or a combination of maxillary retrognathism and mandibular prognathism. ${ }^{1-3}$ The main treatment of choice for Class III malocclusion in young patients is encouragement of maxillary advancement by facemask (FM), considering the high prevalence of maxillary hypoplasia. ${ }^{4,5}$ Pronounced forward movement of the maxilla, mandibular backward rotation, protrusion of upper incisors, retrusion of mandibular incisors, and improvement of the maxillomandibular relationship occurred by FM treatment. ${ }^{6-8}$

The third molars, particularly those in the mandible, are the most frequently impacted teeth. ${ }^{9}$ The reasons for impaction may include morphology and mesiodistal width of teeth, unfavorable path of eruption, inadequate uprighting during eruption, and space in the retromolar region. ${ }^{10-12}$ The backward remodeling and anterior resorption of the ramus and the mesial movement of the dentition seemed to aid the available space for developing second and possibly even third molars in the posterior region. ${ }^{13,14}$ It seems reasonable to question the effects of various types of orthodontic treatments on the potential retromolar space. Few studies have evaluated the effect of orthodontic treatment on mandibular posterior space. ${ }^{11,15,16}$ Fixed orthodontic treatment with premolar extractions was reported to increase the retromolar space and decrease the rate of third molar impaction. ${ }^{11,17}$ A retractive orthopedic force focused on the mandible by the chin part of the FM caused mandibular incisor retrusion..$^{4-7}$ In several studies, the effect of FM on the anterior region of the mandibular dentition was evaluated. ${ }^{4-8}$ In only one study, mandibular posterior space was evaluated at the end of orthopedic Class III treatment, using cephalometric radiographs. ${ }^{18}$ In that study, it was reported that the FM did not affect the mandibular posterior space. However, the presence and position of third molars and long-term effects of FM on the posterior space were not assessed. ${ }^{18}$ There are no studies evaluating the mandibular posterior space on panoramic radiographs after FM treatment that include a long-term evaluation.

The purpose of this retrospective study was to evaluate the mandibular retromolar space at the end of FM treatment and at the end of the long-term follow-up, using panoramic radiographs and by considering the position of third molars.

Disclosure. Authors have no conflict of interests, and the work was not supported or funded by any drug company.
Methods. Approval for this retrospective study was obtained from the Ethical Committee of the Dentistry Faculty of Gazi University (6.11.2007/1) and all participants signed an informed consent agreement. This study was performed according the principles of the Declaration of Helsinki. It was conducted between May and September in 2014 by the Faculty of Dentistry in Gazi University. The sample of this study consisted of pre-treatment (T1), post-treatment (T2), and follow-up (T3) panoramic radiographs of 19 skeletal and dental Class III patients ( 7 female, 12 male) who had maxillary retrusion or a combination of maxillary retrusion and mandibular prognathism treated with a Delaire-type FM and a removable intraoral upper appliance. The mean age at T1 was 10.5 years. Each patient's lower arches were evaluated as right and left segments. As third molars were congenitally absent in 3 segments, a total of 35 segments were evaluated in this study. The inclusion criteria were no missing, decayed, or extracted permanent mandibular teeth (erupted/non-erupted) except third molars and no history of syndromes or systemic diseases that could affect tooth development. Patients who had craniofacial deformity or syndrome, mandibular pathology, supernumerary teeth, history of dento-facial injury or previous orthodontic therapy, or poor image quality of panoramic radiographs were excluded from the study.

We applied $300 \mathrm{~g}$. orthopedic protraction force from the hooks of the upper acrylic removable appliances.

Panoramic radiographs were taken at the beginning of therapy (T1) and after Class I molar relation was obtained with a positive overjet (T2). The average duration of treatment (T2-T1) was one year, and follow-up period (T3-T2) was 2.4 years.

Morita's Veraviewepocs 2D (Kyoto, Japan) operating at optimum tube voltage $(60-90 \mathrm{kV})$ and current (1-10 mA), with an effective $0.5 \mathrm{~mm}$ focal spot and an exposure time of approximately 7.4 seconds was used to obtain all panoramic radiographs. All radiographs were measured manually by the same researcher.

The positions of lower third molar were classified as vertical, horizontal, distoangular, mesioangular, transversal, and inverse, by Winter's classification. ${ }^{19}$ As the eruptions of second molars were not complete at the beginning of treatment, positions of third molars were evaluated according to the first molars instead of second molars used in Winter's classification in this study. Developmental stages of lower third molars were assessed using the Demirjian's classification (Stages A-H).$^{20} \mathrm{On}$ panoramic radiographs, an occlusal line was drawn through the tips of the superior cusp of the lower first premolar and the superior mesial cusp of the lower first 
molar, and the intersection of this line with the ramus was marked as the J point. Mandibular retromolar space (DJ) was measured as the distance between the J point and the point (D) where a perpendicular line from the most distal of the lower first molar intersects the occlusal line. A line tangent to the lower border of the corpus of the mandible was drawn. Long axes of the first and third molars were also drawn, and the following angles were measured: $ß$, third molar angulation, measured between long axis of the lower third molar and the mandibular line; $\Upsilon$, angulation of the lower first molar, measured between the lower first molar and the mandibular line; and $\alpha$, measured between the long axis of the lower first and third molars ${ }^{15}$ (Figure 1).

Statistical analysis. The data were statistically analyzed by using SPSS 15.0 (SPSS Inc, Chicago, Ill.). Kolmogorov-Smirnov and Shapiro-Wilk tests were used to test of normality. According to results, non-parametric tests were preferred. Friedman's 2-way analysis of variance were used to compare the changes of measurements among 3 times and when the p-value from the Friedman test statistics is statistically significant, multiple comparison test was used to know which time interval differs from the others. ${ }^{21}$ The results were given as median (minimum-maximum) in Table 1 and ratio in Table 2 for quantitative and qualitative variables. Fifteen panoramic radiographs were retraced and re-measured after 15 days. Cohen's Kappa statistic is used to evaluate intra-rater agreement and found 0.98 for Demirjian stage and 1.00 for Winter's classification. ${ }^{22}$ Pearson's correlation test was used to determine the association between DJ and $B$ angle; DJ and Demirjian stage. ${ }^{23}$ The statistical significance of Winter's classification in Demirjian stages was evaluated by Monte-Carlo Simulation technique for the Fisher's chi-square statistic. ${ }^{24} \mathrm{~A} p$-value less than 0.05 was considered as significant.
Results. Based on a power analysis that showed that a sample size of 32 segments achieves $80 \%$ power at $\mathrm{p}=0.05$, the sample size was increased to 35 segments in this study. The increase in $\Upsilon$ was significant only for T3 $(p=0.017)$. Mandibular retromolar spaces increased significantly during all periods. There were also significant differences in dental maturation stages according to Demirjian classification during all periods (Table 1). The percentages of angulation of the lower third molar during all periods are shown in Figure

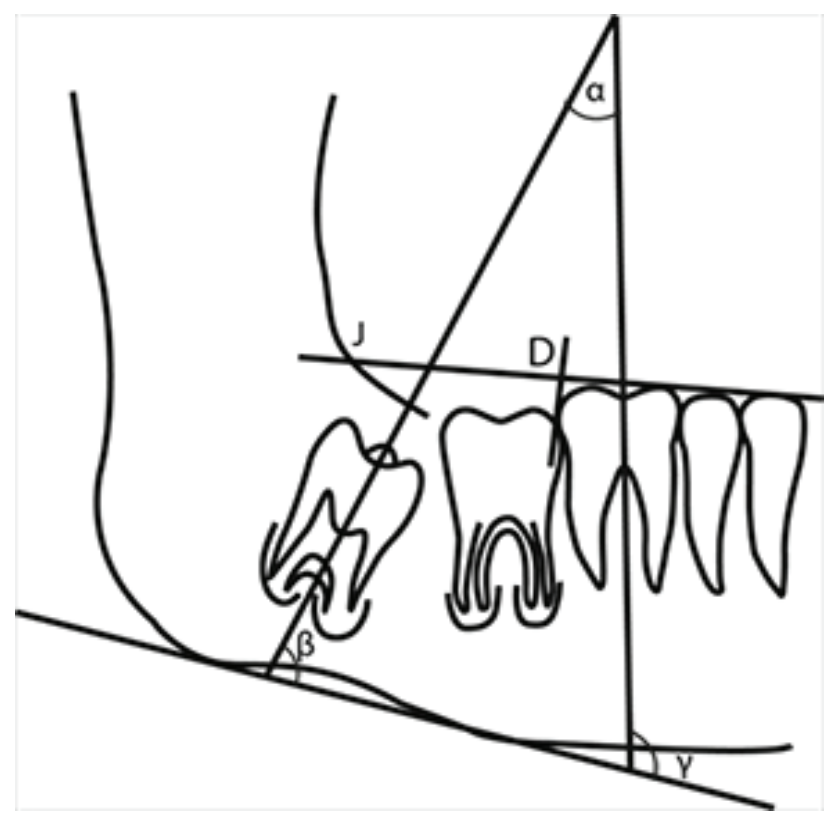

Figure 1 - A schematic drawing of the angulations of first and third molars. $\beta$ angle: Angulation of the third molar; $Y$ angle: Angulation of the first molar; measured between long axis of the lower third molar and the mandibular line; $\alpha$ angle: The angle between the first and third molars; D: The most distal of lower first molar; J: The intersection of an occlusal line drawn through the tips of the superior cusp of the lower first premolar and the superior mesial cusp of the lower first molar teeth with the ramus DJ: Mandibular retromolar space.

Table 1 - Treatment (T1-T2), follow-up (T2-T3), and overall (T3-T1) changes during facemask therapy.

\begin{tabular}{|c|c|c|c|c|c|c|c|}
\hline Variables & $\begin{array}{l}\text { Beginning of treatment }\left(\mathrm{T}_{1}\right) \\
\text { Median (Min.-Max.) }\end{array}$ & $\begin{array}{l}\text { End of treatment }\left(\mathrm{T}_{2}\right) \\
\text { Median (Min.-Max.) }\end{array}$ & $\begin{array}{l}\left.\text { After follow-up ( } \mathrm{T}_{3}\right) \\
\text { Median (Min.-Max.) }\end{array}$ & p-value & $\mathrm{p}(\mathrm{T} 2-\mathrm{T} 1)$ & $\mathrm{p}(\mathrm{T} 3-\mathrm{T} 2)$ & $\mathrm{p}(\mathrm{T} 3-\mathrm{T} 1)$ \\
\hline$\alpha\left(^{0}\right)$ & $38.75(1.00-71.50)$ & $35.75(9.50-74.00)$ & $34.00(10.00-84.50)$ & 0.570 & NS & NS & NS \\
\hline$B\left({ }^{0}\right)$ & $61.00(22.50-91.00)$ & $62.25(20.50-86.50)$ & $69.75(12.50-91.00)$ & 0.570 & NS & NS & NS \\
\hline$\Upsilon\left({ }^{0}\right)$ & $96.75(70.00-112.00)$ & $97.75(76.50-116.00)$ & $99.75(85.00-119.50)$ & 0.028 & 0.169 & 0.003 & 0.017 \\
\hline DJ (mm) & $17.50(12.50-29.00)$ & $20.50(9.00-31.00)$ & $24.50(13.00-33.00)$ & $<0.001$ & $<0.001$ & $<0.001$ & $<0.001$ \\
\hline $\begin{array}{l}\text { Demirjian staging } \\
\text { of lower third } \\
\text { molar }\end{array}$ & $\mathrm{B}(\mathrm{A}-\mathrm{D})$ & $\mathrm{D}(\mathrm{B}-\mathrm{E})$ & $\mathrm{E}(\mathrm{C}-\mathrm{F})$ & $<0.001$ & $<0.001$ & $<0.001$ & $<0.001$ \\
\hline
\end{tabular}


2. The vertical angulation was the most common position of third molars at T1 $(60 \%), \mathrm{T} 2(80 \%)$, and T3 $(82.9 \%)$. The next most common position was found to be the horizontal angulation at T1 (28.6\%), T2 (14.3\%), and T3 (14.3\%) (Figure 2). Moderate and significant correlations were found between DJ and $B$ at T2 $(p=0.037)$ and T3 $(p=0.024)$ (Figure 3). Significant correlations were also found between DJ and Demirjian classification stages during all periods (Figure 4). Significant correlations were determined between Demirjian's stages and Winter's classification of lower third molars at T2 $(p=0,013)$ and T3 $(p<0.001)$ (Table 2).

Discussion. There are several factors affecting the possibility of the lower third molar impaction. Significant reduction in the rate of lower third-molar impaction in orthodontic treatment with premolar extractions was reported due to the increase in posterior space. ${ }^{16}$ However, limiting the DJ may result in the impaction of the third molars. ${ }^{25-27}$ Therefore, the posterior dental arch should be included in orthodontic treatment plans to achieve stable results. Only one study has previously evaluated DJ at the end of the FM therapy in Class III subjects, and this was without considering third molar position. ${ }^{18}$ The present retrospective study was performed to assess DJ after FM therapy and a long-term follow-up period. The positions, angulations, and dental maturations of lower third molars were also evaluated. Maxillary protraction with FM is a common therapy choice for skeletal Class III malocclusion due to maxillary deficiency. ${ }^{1}$ In the present study, all patients were treated with Delaire-type FM and a removable intraoral upper appliance, and DJ was determined by panoramic radiograph. Tronje et $\mathrm{al}^{28}$ reported

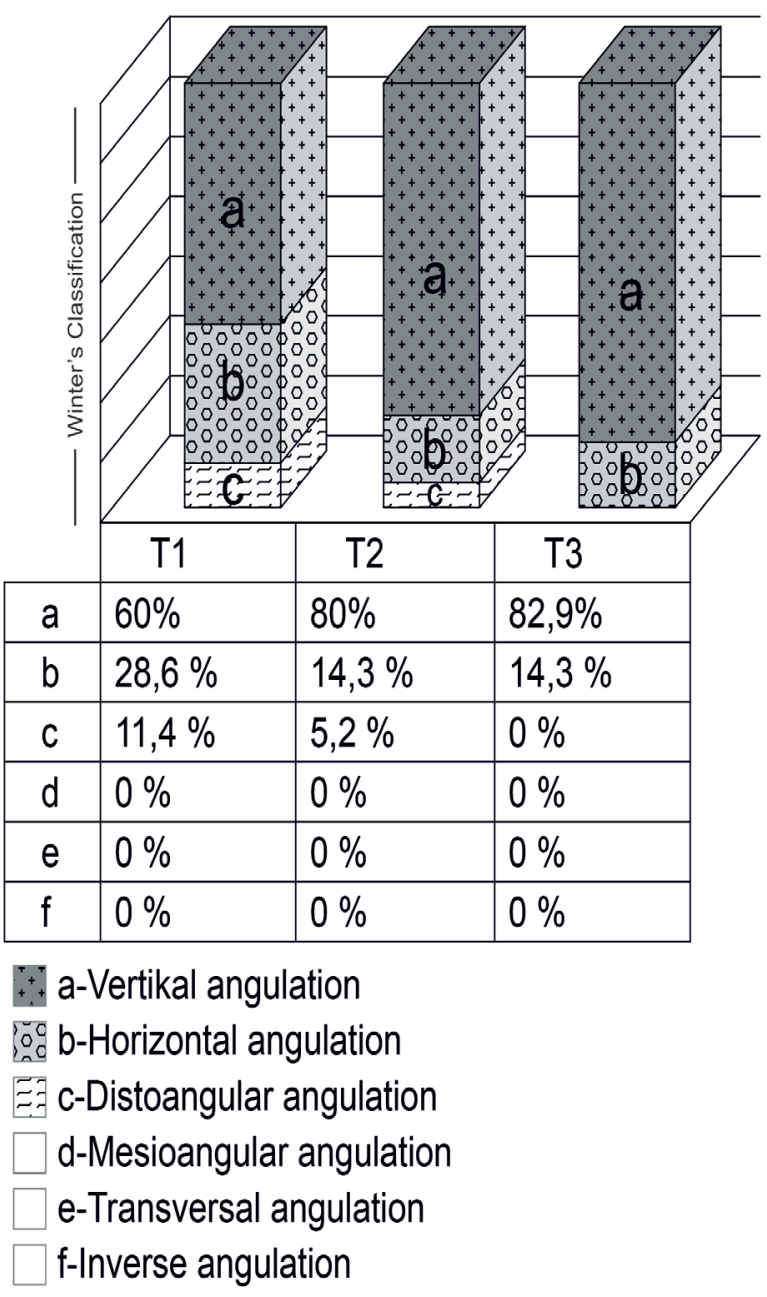

Figure 2 - The positions of lower third molar according to their angulation to the long axis of the first molar during periods regarding Winter's classification. T1: Pre-treatment; T2: Posttreatment; T3: Follow-up.
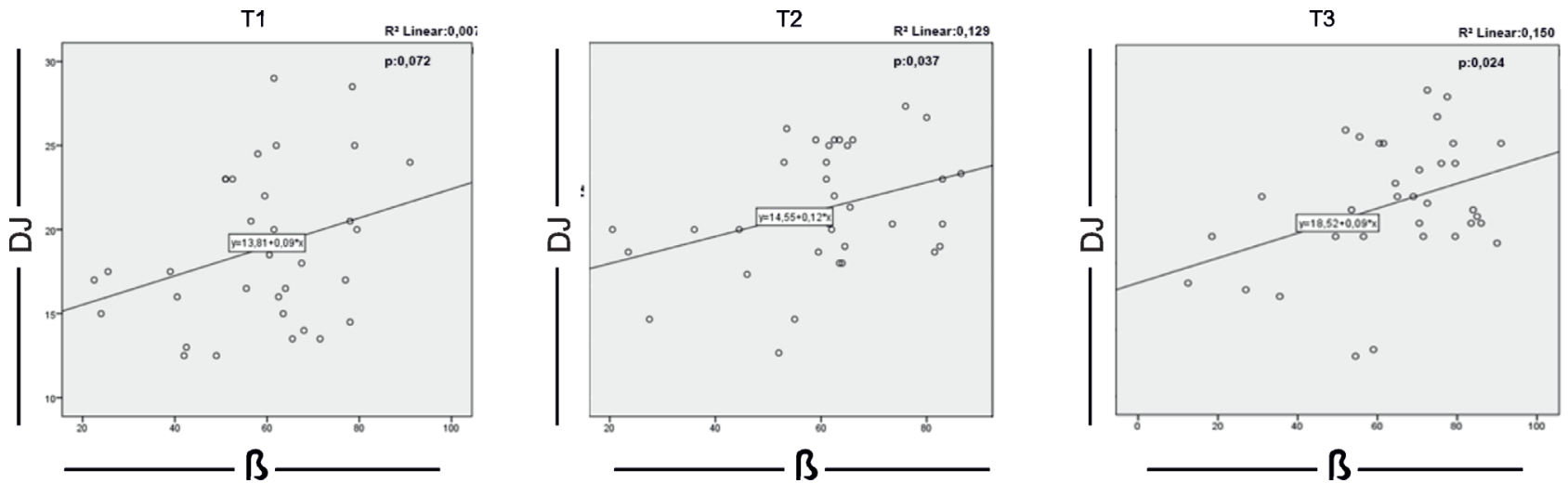

Figure 3 - The correlations between mandibular retromolar space (DJ) and third molar angulation (ß). T1: Pre-treatment; T2: Post-treatment; T3: Followup. 

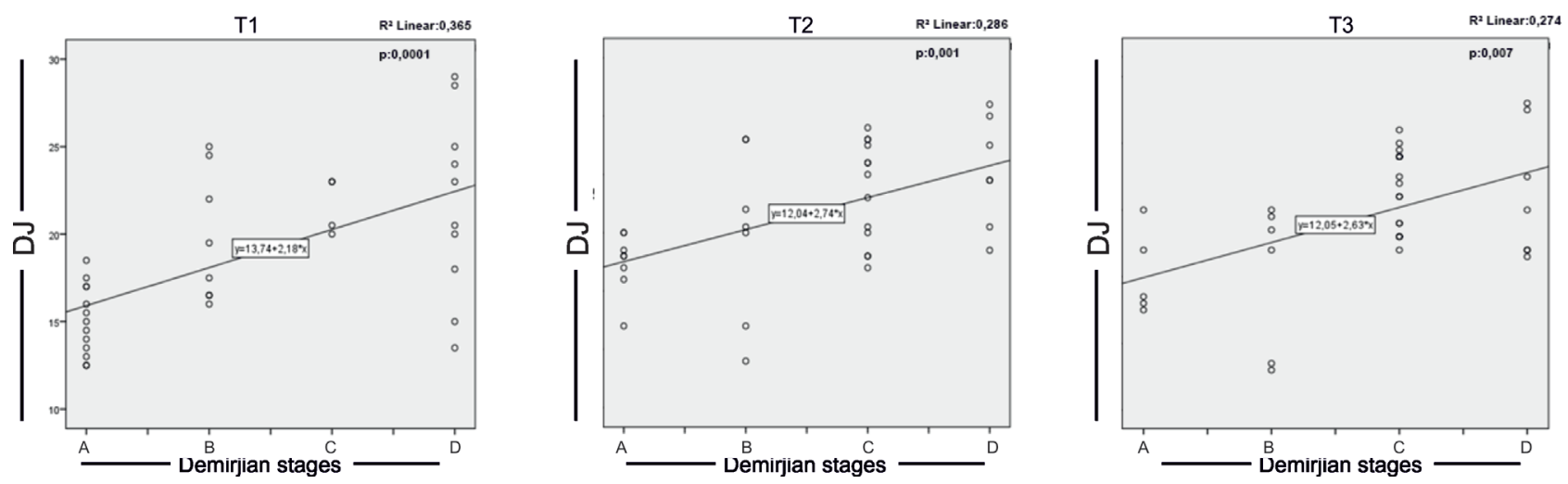

Figure 4 - The correlations between mandibular retromolar space (DJ) and Demirjian stages during periods. T1: Pre-treatment; T2: Post-treatment; T3: Follow-up.

Table 2 - According to Demirjian's stages, the distribution of third molar's position.

\begin{tabular}{|c|c|c|c|c|c|c|c|c|c|c|c|c|c|c|c|c|}
\hline \multirow{3}{*}{$\begin{array}{l}\text { Winter's } \\
\text { Classification }\end{array}$} & \multicolumn{15}{|c|}{ Demirjian's stages } & \multirow{3}{*}{$p$-value } \\
\hline & \multicolumn{4}{|c|}{$\mathrm{T} 1$} & \multirow{2}{*}{\multicolumn{2}{|c|}{$p$-value }} & \multicolumn{3}{|c|}{$\mathrm{T} 2$} & \multirow{2}{*}{\multicolumn{2}{|c|}{$p$-value }} & \multicolumn{4}{|c|}{ T3 } & \\
\hline & & A & B & $\mathrm{C}$ & & & A & B & $\mathrm{C}$ & & & A & B & $\mathrm{C}$ & D & \\
\hline $\mathrm{a}$ & & $(46.2)$ & $5(62.5)$ & $3(75.0)$ & $7(70)$ & & $4(50)$ & $6(85.7)$ & $11(84.6)$ & $7(100)$ & & $1(20)$ & $5(83.3)$ & $17(100)$ & $6(85.7)$ & \\
\hline $\mathrm{b}$ & & $(46.2)$ & $3(37.5)$ & $1(25.0)$ & $0 \quad(0)$ & & $4(50)$ & $1(14.3)$ & $0(0)$ & $0(0)$ & & $4(80)$ & $1(16.7)$ & $0(0)$ & $0(0)$ & \\
\hline c & 1 & (7.7) & $0(0)$ & $0(0)$ & $3(30)$ & 0.131 & $0 \quad(0)$ & $0(0)$ & $2(15.4)$ & $0(0)$ & & $0(0)$ & $0(0)$ & $0(0)$ & $0(0)$ & \\
\hline \multirow[t]{2}{*}{ d } & & $0(0)$ & $0(0)$ & $0(0)$ & $0 \quad(0)$ & & $0 \quad(0)$ & $0(0)$ & $0(0)$ & $0(0)$ & $0.013^{*}$ & $0(0)$ & $0(0)$ & $0(0)$ & $1(14.3)$ & $p<0.001 \dagger$ \\
\hline & 13( & $(100.0)$ & $8(100.0)$ & $4(100.0)$ & $10(100)$ & & $8(100)$ & $7(100)$ & $13(100)$ & $7(100)$ & & $5(100)$ & $6(100.0)$ & $17(100)$ & $7(100.0)$ & \\
\hline
\end{tabular}

that panoramic radiographs were as reliable as lateral cephalograms for geometric measurements. Stramotas et $\mathrm{al}^{29}$ stated that elongation error in the panoramic radiographs is mostly due to the magnification factor, and if the radiographs are exposed on the same panoramic radiographic equipment at different times, the apparent lengths of the teeth remain constant. In this study, all panoramic radiographs were taken on the same cephalostate with the same magnification. Bouwens et $\mathrm{al}^{30}$ reported that panoramic radiographs provide less reliable information regarding angulations of the teeth. While assessing the angulations with panoramic images, the radiographic data should be combined with a detailed intraoral examination. Cone beam computed tomography (CBCT) was offered as a powerful tool for the visualization of root angulation. ${ }^{30}$ However, it is not ethically approved to use CBCT for the evaluation of therapy effects. In this study, DJ was increased approximately $3 \mathrm{~mm}$ during FM therapy and $4.5 \mathrm{~mm}$ during the 2.4 years of the follow-up period. Tortop et $\mathrm{al}^{18}$ found a significant increase in DJ during FM treatment. They reported that this increase showed no significant difference compared to that of the control group. Chen et $\mathrm{al}^{31}$ reported a $1.5 \mathrm{~mm}$ increase per year in Class I patients less than 16 years old. Bjork ${ }^{13}$ found 1.5 $\mathrm{mm}$ of increase in the posterior dental arch on each side per year until ages 14 years for girls and 16 years for boys. In the current study, increase in DJ during the follow-up period seemed to be in accordance with these previous studies. ${ }^{10,31}$ In this study, insignificant uprighting of $1.3^{\circ}$ and $7.5^{\circ}$ in $B$ were found during treatment and follow-up periods. The tooth buds of molars have been reported to be generally mesially angulated during the initial stages of calcification and root development. ${ }^{32}$ Longitudinal assessments show the uprighting of the lower third molars in the subjects without history of orthodontic treatment during early adolescence. ${ }^{32}$ Richardson ${ }^{27}$ also reported that minimal uprighting of third molars might increase the impaction risk. In a recent comprehensive study, it was demonstrated that the rate of lower third-molar impaction was reduced significantly during fixed orthodontic treatment in extraction patients as compared with that in nonextraction patients. ${ }^{16}$ This might be attributed to forward movement of the molars during closure of the extraction space, thereby increasing the DJ. In light 
of this finding, DJ should be included in orthodontic treatment plans. In this study, there were no significant differences in $\Upsilon$ during FM treatment. Though Class III treatments using removable appliance resulted with a distal tipping of mandibular first molars, ${ }^{33,34}$ in a study insignificant changes were reported during treatment with a combined FM and Alt-RAMEC protocol. ${ }^{33} \mathrm{~A}$ significant uprighting of the lower first molar during the follow-up period was observed in the present study. The lesser increase in DJ during the follow-up period could be related to the significant uprighting of these teeth. In this study, Demirjian's method was used to determine dental age. Using this method, root and crown developments were evaluated in 8 stages from $\mathrm{A}$ to $\mathrm{H}^{35,36}$ The developmental stage of the lower third molars was stage B at the beginning of FM treatment (mean age: 10.5 years). The crown formation of the third molar was completed (Stage D) at the end of the treatment (T2) and it was stage E after 2.4 years of follow-up (T3). Significant correlations were found between DJ and Demirjian classification stages during all periods. This finding is in accordance with the results of Ghougassian et $\mathrm{al}^{37}$ who reported a high correlation between the dental maturation stage of third molar and DJ. The angulation of impacted third molars is usually determined by visual impression based on Winter's classification. ${ }^{19}$ In this study, we used this practical and effective classification for determination of angulation of impacted third molars during treatment and follow-up periods. The numbers of vertically angulated third molar were 21 at T1, 28 at T2, and 29 at T3 periods. The number of horizontally angulated third molars was 10 at T1 and decreased to 5 at T3. During all periods, vertical angulation was the most common position of lower third molars, followed by horizontal angulation. In support of our findings, Gregory and Larry $^{38}$ reported that normal rotation of third molars is expected to occur from horizontal to mesioangular and from mesioangular to vertical. Normando ${ }^{39}$ suggested retaining third molars until the end of orthodontic treatment. However, in mandatory situations that could possibly hinder orthodontic treatment, removal of third molars at the beginning of the treatment can be an appropriate strategy. ${ }^{39}$ As the findings of this study showed that horizontal angulation turned to a vertical direction during follow-up, it could be interpreted that a follow-up evaluation of third molar position after treatment may contribute to the increased possibility of eruption and, in case of extraction, a less traumatic surgical procedure might be achieved. In this study, significant moderate correlations were found between $B$ and DJ at the end of the treatment and follow-up periods.
This may be due to the increased anterior resorption of the ramus caused by the uprighting of the third molars. Growth might be attributed to the increase in DJ, so the lack of a control group was a limitation for this study. For ethical purposes, it was not possible to find a Class III untreated control group for such a follow-up period. Follow-up studies conducted using both the lateral cephalometric and panoramic radiographs are needed to show the accurate relationship between the DJ and impaction of lower third molars after Class III treatment. It should be also considered that the results of this study must be reevaluated after observing the eruption of the third molars.

In conclusion, facemask therapy did not have an adverse effect on the mandibular retromolar space during treatment and follow up period. Horizontal angulation of lower third molars seemed to turn into a vertical direction, suggesting that it might be better to make a surgical extraction decision after a follow-up period.

\section{References}

1. Ngan P, Moon W. Evolution of Class III treatment in orthodontics. Am J Orthod Dentofacial Orthop 2015; 148: 22-36.

2. Guyer EC, Ellis EE, McNamara JA Jr, Behrents RG. Components of Class III malocclusion in juveniles and adolescents. Angle Orthod 1986; 56: 7-30.

3. Ming Y, Hu Y, Li Y, Yu J, He H, Zheng L. Effects of maxillary protraction appliances on airway dimensions in growing class III maxillary retrognathic patients: A systematic review and meta-analysis. Int J Pediatr Otorhinolaryngol 2018; 105: 138-145.

4. Yepes E, Quintero P, Rueda ZV, Pedroza A. Optimal force for maxillary protraction facemask therapy in the early treatment of class III malocclusion. Eur J Orthod 2014; 36: 586-594.

5. Rathi AR, Kumari NR, Vadakkepuriyal K, Santhkumar M. Treatment of skeletal class III malocclusion using face mask therapy with alternate rapid maxillary expansion and constriction (Alt-RAMEC) protocol. J Indian Soc Pedod Prev Dent 2015; 33: 341-343.

6. Cordasco G, Matarese G, Rustico L, Fastuca S, Caprioglio A, Lindauer SJ, et al. Efficacy of orthopedic treatment with protraction facemask on skeletal Class III malocclusion: a systematic review and meta-analysis. Orthod Craniofac Res 2014; 17: 133-143.

7. Foersch M, Jacobs C, Wriedt S, Hechtner M, Wehrbein H. Effectiveness of maxillary protraction using facemask with or without maxillary expansion: a systematic review and metaanalysis. Clin Oral Investig 2015; 19: 1181-1192.

8. Koh SD, Chung DH.Comparison of skeletal anchored facemask and tooth-borne facemask according to vertical skeletal pattern and growth stage. Angle Orthod 2014; 84: 628-633.

9. Eshghpour M, Nezadi A, Moradi A, Shamsabadi RM, Rezaei NM, Nejat A.Pattern of mandibular third molar impaction: A cross-sectional study in northeast of Iran. Niger J Clin Pract 2014; 17: 673-677. 
10. Juodzbalys G, Daugela P. Mandibular third molar impaction: review of literature and a proposal of a classification. J Oral Maxillofac Res 2013; 4: e1.

11. Behbehani F, Artun J, Thalib L. Prediction of mandibular third-molar impaction in adolescent orthodontic patients. Am J Orthod Dentofacial Orthop 2006; 130: 47-55.

12. Abu Alhaija ES, AlBhairan HM, AlKhateeb SN. Mandibular third molar space in different antero-posterior skeletal patterns. Eur J Orthod 2011; 33: 570-576.

13. Bjork A, Skieller V. Normal and abnormal growth of the mandible: A synthesis of longitudinal cephalometric implant studies over a period of 25 years. Eur J Orthod 1983; 5: 1-46.

14. Bishara SE, Jakobsen JR, Treder J, Nowak A. Arch length changes from 6 weeks to 45 years. Angle Orthod 1998; 68: 69-74.

15. Turkoz C, Ulusoy C. Effect of premolar extraction on mandibular third molar impaction in young adults. Angle Orthod 2013; 83: 572-577.

16. Kim TW, Artun J, Behbehani F, Artese F. Prevalence of third molar impaction in orthodontic patients treated nonextraction and with extraction of four premolars. Am J of Orthod Dentofacial Orthop 2013; 123: 138-145.

17. Richardson ME. The effect of mandibular first premolar extraction on third molar space. Angle Orthod 1989; 59: 291-294.

18. Tortop T, Kaygisiz E, Erkun S, Yuksel S. Treatment with facemask and removable upper appliance versus modified tandem traction bow appliance: the effects on mandibular space. Eur J Orthod 2017; 20: [Epub ahead of print]

19. Winter GB. Principles of exodontia as applied to the impacted third molars. St. Louis: American Medical Books; 1926.

20. Demirjian A, Goldstein H, Tanner JM. A new system of dental age assessment. Hum Biol 1973; 45: 221-227.

21. Siegel S, Castellan NJ Jr. Nonparametric Statistics for the Behavioral Sciences. The Friedman Two-way analysis of variance by Ranks. McGraw-Hill Inc. (NY): USA; 1988. p. 174-183.

22. Cohen J. A coefficient of agreement for nominal scales. Educ Psychol Meas 1960; 20: 37-46.

23. Agresti A. Introduction to Categorical Data Analysis. 2nd ed. New York (NY): John Wiley and Sons; 1996. p. 231-236.

24. Fisher RA. On the interpretation of $\Upsilon 2$ from contingency tables, and the calculation of P. J. R Stat Soc 1922; 85: 87-94.

25. Bishara SE, Andreasen G. Third molars: a review. Am J Orthod 1983; 83: 131-137.

26. Brezulier D, Fau V, Sorel O. Influence of orthodontic premolar extraction therapy on the eruption of the third molars: A systematic review of the literature. J Am Dent Assoc 2017; 148: 903-912.
27. Richardson ME. The etiology and prediction of mandibular third molar impaction. Angle Orthod 1977; 47: 165-172.

28. Tronje G, Welander U, McDavid WD, Morris CR. Image distortion in rotational panoramic radiography. I. General considerations. Acta Radiol Diagn 1981; 22: 295-299.

29. Stramotas S, Geenty JP, Darendeliler MA, Byloff F, Berger J, Petocz P. The reliability of crown-root ratio, linear and angular measurements on panoramic radiographs. Clin Orthod Res 2000; 3: 182-191.

30. Bouwens DG, Cevidanes L, Ludlow JB, Philips C. Comparision of mesiodistal root angulation with post-treatment panoramic radiographs and cone-beam computed tomography. Am J Orthod Dentofacial Orthop 2011; 139: 126-132.

31. Chen LL, Xu TM, Jiang JH, Zhang XZ, Lin JX. Longitudinal changes in mandibular arch posterior space in adolescents with normal occlusion. Am J Orthod Dentofacial Orthop 2010; 137 : 187-193.

32. Richardson ME. Development of the lower third molar from 10 to 15 years. Angle Orthod 1973; 43: 191-193.

33. Canturk BH, Celikoglu M. Comparison of the effects of face mask treatment started simultaneously and after the completion of the alternate rapid maxillary expansion and constriction procedure. Angle Orthod 2015; 85: 284-291.

34. Slutzkey S, Levin L. Gingival recession in young adults: Occurrence, severity, and relationship to past orthodontic treatment and oral piercing. Am J Orthod Dentofacial Orthop 2008; 134: 652-656.

35. Nur BG, Altunsoy M, Akkemik O, Ok E, Evcil MS. Third molar mineralization and eruption correlated to chronologic age in Turkish children and adolescents. Australian J Forensic Sci 2015; 47: 1-9.

36. Arany S, Iino M, Yoshioka N. Radiographic survey of third molar development in relation to chronological age among Japanese juveniles. J Forensic Sci 2004; 49: 534-538.

37. Ghougassian SS, Ghafari JG. Association between mandibular third molar formation and retromolar space. Angle Orthod 2014; 84: 946-950.

38. Gregory MN, Larry JP. Impacted teeth. In: Michael M, Ghali GE, Peter EL, Peter DW, editors. Peterson's Principles of Oral and Maxillofacial Surgery. 2nd ed. Hamilton (CA): B. C. Decker, Inc.; 2004. p. 139-140.

39. Normando D. Third molars. To extract or not to extract? Dental Press J Orthod 2015; 20: 17-18. 